\title{
Effect of Forced Molting on Body Characteristics and Post-Molting Egg Production Performance of Layers in Quetta, Pakistan
}

\section{-Author(s)}

\section{Rafeeq $\mathrm{M}^{\prime}$}

Rashid $N^{\prime}$

Awan MA'

Tariq $\mathrm{MM}^{\prime}$

Abbas $\mathrm{F}^{\prime}$

Ahmed Z

Taj I'

Centre for Advanced Studies in Vaccinology and Biotechnology (CASVAB) University of Balochistan Quetta, Pakistan

\section{Mail Adress}

Corresponding author e-mail address Majed Rafeeq

E-mail: majid_casvab@yahoo.com Phone: Off0092 812843853

Hand Phone0092 3337897613

Office Fax 00928129213134

\section{nKeywords}

Layer, force molting, body characteristics, production performance.

\section{ABSTRACT}

White leghorn layer $(n=2740)$, with 85weeksof age, were submitted to forced molting by fasting for 13 days and changes in body characteristics and subsequent laying performance during second laying cycle were evaluated. Live body weight (LBW), ovary weight (OW), oviduct weight (OvW) and oviduct length (OvL) were measured before and after fasting. Post-fasting restricted feeding was applied, initially feeding crushed corn with added $2 \%$ Ca for 20 days and thereafter layer crumble feed was offered. Layers lost $632.16 \mathrm{~g}(36 \%)$ of their LBW and significant reductions of 45.32 , 47.53 and $54 \%$ were observed in post-fasting/molt OW, OvW and $O v L$, respectively $(p<0.05)$. Resting period was 49 days and birds consumed $4.79 \mathrm{~kg}$ feed during resting period. Egg production reached $50 \%$ in the $3^{\text {rd }}$ week and peak mean egg production $(87 \%)$ was recorded between 13 to $16^{\text {th }}$ weeks of production. Hence, it is concluded that while molting exhausted layers, the procedure adapted to induce molting and season would be a core factor in the subsequent laying cycle egg production and gain.

\section{INTRODUCTION}

Molting in nature or induced by farmer has the same effect: a marked loss in body weight (Bell, 1992), renewal of feathering, rejuvenation of the flock with higher egg production and improvements in egg quality (Bar, 1999; Bell, 2003). Forced molting is a management tool and has been practiced for many years. It may involve different procedures, such as withdrawal of water and feed, feeding of low sodium (Harms, 1990) or high zinc levels (Berry \& Brake, 1987; Bell \& Kuney, 1992). The manipulation of the hormonal system (Bass et al. 2007) appeared successful to inducing molting, allowing a second or third cycle of production and maximizing post-molt egg production. Forced molting prevents age-related declines in egg production and eggshell quality (Hussein, 1996; Hassanabadi \& Kermanshahi, 2007). Similarly, age at molting, deprivation duration, type of post-deprivation diet (Bell, 1992) are important factors that affect performance of molted hens when feed deprivation molting methods are used (Bell \& Kuney, 1992; Bell \& Adams 1992; Bar et al. 2001).

Molting results in certain changes in body characteristics. This includes feather and body weight loss and regression of the liver, ovary and oviduct in hens. Loss of wing feathers is a morphological characteristic that indicated the beginning of molting. Body weight loss could be due to a reduction of adipose tissue and regression of visceral organs. It is reported that $25 \%$ of total body weight loss was directly attributed to regression of the liver, ovary and oviduct (Brake \& Thaxton, 1979; Andrews et al. 1987). 
The recent increase in the price of inputs (feed and chicks) adversely affected layer farming at local level. Forced molting of the laying hens to increase income and limit costs during second laying cycle has been practiced for many years in different parts of the world and could be feasible procedure to be adopted. The objective of the present study was to evaluate the effect of forced molting on body characteristics of layers, resting period feed cost and the subsequent performance of the molted layer during the second laying cycle.

\section{MATERIAL AND METHODS}

Twenty seven hundred and forty $(n=2740)$ white leghorn layers with85 weeks of age were submitted to forced molting in January, 2010, in a private poultry farm. A fasting period of 13 days was applied to cause molting. Birds were taken out of the cages and kept on the floor. Water supplemented with vitamins was supplied ad libitum during the fasting period and no artificial lighting was provided. Pre- and post-molting live body weight (LBW) was recorded by randomly weighing $2 \%$ of the birds. Ovary weight (OW), oviduct weight (OvW), and oviduct length (OvL) were recorded by randomly taking 10 birds for slaughtering each for pre-and post-molting periods respectively.

At the end of the fasting period, bird were restricted fed, initially receiving $30 \mathrm{~g} / \mathrm{b} / \mathrm{d}$, which was gradually increased until $110 \mathrm{~g} / \mathrm{b} / \mathrm{d}$ was reached. The birds were fed ground corn with the addition of $2 \% \mathrm{Ca}$ as $\mathrm{CaCO}_{3}$ for the first20 days and a layer crumble commercial feed there after (Hurwitz et al. 1998). Feed offer was weekly adjusted to mortality. Birds were re-caged on day 20post-fasting. Hours of light started to increase after one week feeding was resumed, and were gradually increased to 16 hours. Feed in take $(\mathrm{kg})$, feed cost per bird in rupees (Rs.) during resting period, average weekly egg production (number of saleable eggs collected) and feed cost were calculated.

The obtained data were submitted to statistical analysis using Student's t-test for changes in body characteristic changes and average for production parameters using computer software SPPSS 16 for windows.

$$
t=\frac{\bar{x}_{1}-\bar{x}_{2}}{\sqrt{\frac{s_{1}^{2}}{n_{1}}+\frac{s_{2}^{2}}{n_{2}}}}
$$

\section{RESULTS}

In order to induce molting laying hens were fasted for 13 days. Egg production of the first egg laying cycle completely ceased on day 4 of the fasting period.

Mean LBW, OW, OVW and Ovl results obtained in the pre- and post-fasting period are presented in Table 1. Mean LBW of the layers was $1756 \pm 3.84 \mathrm{~g}$ and $1123 \pm 3.15 \mathrm{~g}$ for pre- and post-fasting periods, respectively. Birds lost $632.16 \mathrm{~g}(36 \%)$ of their body weight at the end of fasting, in average $(p<0.05)$. Similarly, a significant decrease $(p<0.05)$ in OW, OvW and OVL (45.32, 47.53 and 54\%, respectively) was observed after the fasting period.

The results of post-fasting resting period mortality, feed in take and feed cost of layers are presented in Table 2. Post-fasting/resting period observed was 49 days and feed cost during the resting period was Rs. 112.188 per live bird (1US\$= 85 Rupees).

Mean daily egg production (\%) and net gain in rupees (Rs) during the laying cycle is presented in Figure1. During second laying cycle, 50\% egg production was achieved in third week and peak egg production (87\%)was achieved between 13 and 16 weeksof egg production, respectively. Maximum net gain was observed between weeks 41 and 44 .

Table 1 - Pre- and Post molting ovary weight (OW), oviduct weight (OvW) and oviduct length (OvL) of layers (Mean \pm SEM)

\begin{tabular}{lcccc}
\hline Period & $\begin{array}{c}\text { Live weight } \\
(\mathrm{g})\end{array}$ & $\begin{array}{c}\text { Ovary } \\
\text { weight } \\
(\mathrm{g})\end{array}$ & $\begin{array}{c}\text { Oviduct } \\
\text { weight } \\
(\mathrm{g})\end{array}$ & $\begin{array}{c}\text { Oviduct } \\
\text { length } \\
(\mathrm{cm})\end{array}$ \\
\hline Pre-molting & $\begin{array}{c}1756.0^{\mathrm{a}} \pm \\
14.96^{\mathrm{a}} \pm\end{array}$ & $\begin{array}{c}69.46^{\mathrm{a}} \pm \\
0.79\end{array}$ & $59^{\mathrm{a}} \pm 0.95$ \\
& 3.84 & 0.11 & 0.79 & \\
Post-molting & $1123.8^{\mathrm{b}} \pm$ & $6.78^{\mathrm{b}} \pm 0.15$ & $33.02^{\mathrm{b}} \pm$ & $32^{\mathrm{b}} \pm 0.56$ \\
& 3.15 & & 0.42 & \\
\% Change & 36.00 & 45.32 & 47.53 & 54.00 \\
\hline
\end{tabular}

* Means in the same column with different superscript aresignificantly different $(\mathrm{P}<$ $0.05)$

Table 2 - Post-fasting resting period weekly mortality (\%), feed intake $(\mathrm{kg})$ and feed cost per bird (Rs.) of layers

\begin{tabular}{lccc}
\hline Weeks & Mortality (\%) & Feed intake $(\mathrm{kg})$ & Feed cost (Rs.) \\
\hline 1 & 4.376 & 612.04 & 6.0528 \\
\hline 2 & 0.977 & 1530.68 & 15.8304 \\
\hline 3 & 0.269 & 1716.33 & 17.9256 \\
\hline 4 & 0.180 & 1711.71 & 18.095 \\
\hline 5 & 0.000 & 1708.63 & 18.095 \\
\hline 6 & 0.135 & 1708.63 & 18.095 \\
\hline 7 & 0.000 & 1706.32 & 18.095 \\
\hline
\end{tabular}




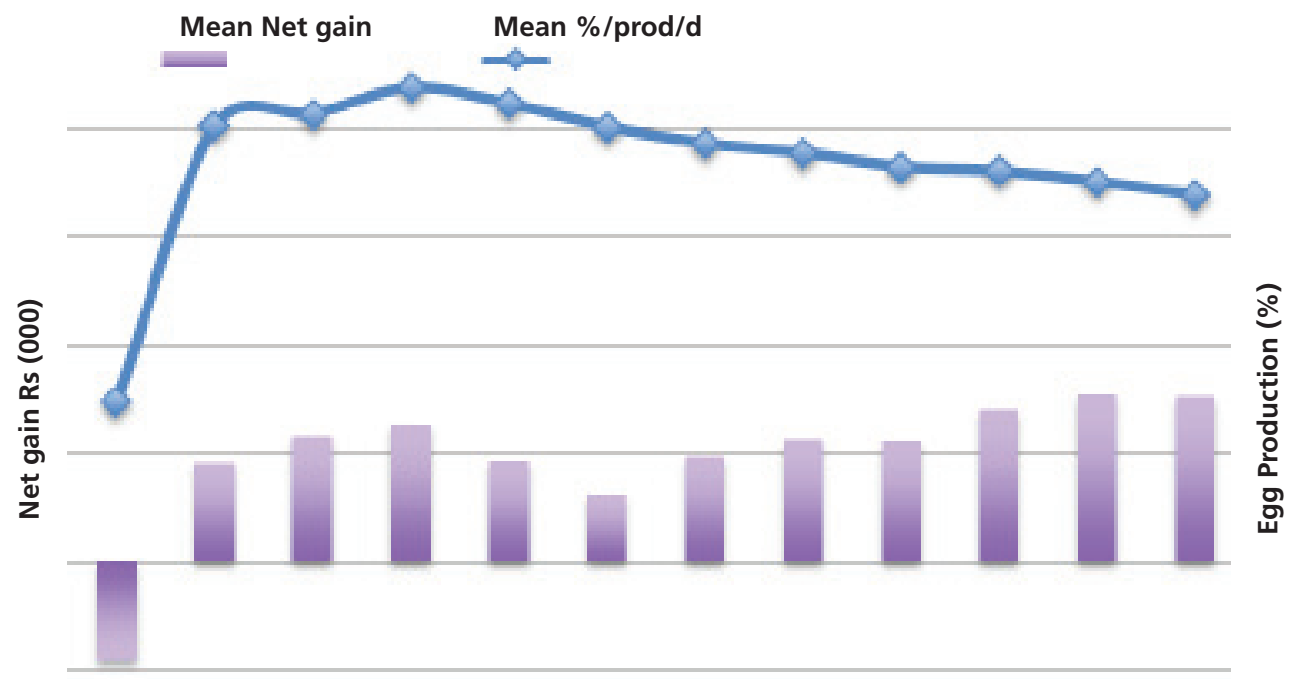

Figure 1: Relation between egg production (\%) and net gain Rs.

\section{DISCUSSION}

Different methods of molting are practiced, all presenting advantages and limitations. In the present study, fasting for the period of 13 days was adopted and $36 \%$ body weight loss was observed. Because birds were fasted in an open house during winter, this could have caused this excessive live body weight loss. Almost same body weight loss results, ranging between 24 and31\%, were reported in molted layers by some authors(Baker et al. 1983; Andrews et al. 1987; Bell, 1992; and Oguike et al. 2005), while Hassanabadi \& Kermanshahi (2007) withdrawal feed for five days and reported 20\% weight loss. Consistently, Bass et al. (2007) reported more body weight loss in complete feed with draw al treatments and faster regain when ad libitum feed was offered. Andrews et al. (1987) reported that $25 \%$ of total body weight loss was directly attributed to regression of the liver, ovary and oviduct. Ocak et al. (2004) suggested that lighter hens loose more weight during molting. In a study with Japanese quails, Kashmiri \& Vatsalya (2011) reported that forced molting resulted in body weight loss, regression of reproductive organs and decrease in the size of liver.

The birds in the present study were submitted to molting at the age of 85 weeks and egg production stopped immediately on day 4 of fasting, while, Halaby (1997) fed a diet with $60 \%$ raw bitter vetch seed and obtained cessation of egg production within 2 weeks. It could be suggested that complete feed withdrawal immediately ceases egg production because fasting results in changes in the normal physiology in terms of reduced digestive enzyme, serum cholesterol, triglycerides and very low density lipoproteins (VLDL), which are important for egg production (Baranczuk et al. 1995; Peebles et al. 2004); however, there is individual variation among birds.

Mean ovary and oviduct weights were significantly lower at the end of fasting. The findings of the present study are in line with Brake \& Thaxton (1979), who reported smaller but healthier ovaries and oviduct during the post-molting phase. Mortality during the fasting was very high possibly due to the excessive body weight loss and age of the birds.

Bell \& Adams (1992) suggested that age at molting and type of post-deprivation diet affected performance of molted hens when feed deprivation methods are applied. It was reported that fasting to induce molting results in cessation of egg production and it varies as a function of the length of time that the hens are fasted (Berry, 2003). The resting period in the present study was 49 days contrary to Bass et al. (2007), who fed hens ad libitum feed and egg production started on day 56 . In the present study as the layers were fed corn with added calcium for initial 20 days and thereafter a layer crumble feed containing $2700 \mathrm{kcal} / \mathrm{kg}$ and $17 \% \mathrm{CP}$ as claim by the producer. Similar nutrient levels were reported by Ocak et al. (2004), while relatively higher energy levels were suggested by Hassan et al. (2000), Bar et al.(2001) and Wu et al.(2007) for optimal performance 
during second cycle phase. Koelkebeck et al. (1991) and Alodan \& Mashaly (1999) observed that a fasting period of 10 days and a post-molting diet with $16 \%$ crude protein resulted in better layer performance. Age at molting also plays a vital role in the second cycle egg production.

Different studies also reported that flocks fasted up to 10 days reached $50 \%$ production by eight weeks from the initiation of fasting (Swanson \& Bell, 1971; Berry, 2003); however, weight loss during fasting plays a vital role and more than 35\% decrease in body weight may result in delayed initiation of egg production and reduced number of eggs over the life of the flock (Carter \& Ward, 1981). In the present study, the post-fasting resting period was seven weeks and $50 \%$ egg production was achieved in the third week of production, in agreement with earlier reports. Delayed initiation and longer time to reach 50\% and peak egg production may be due to excessive body weight loss and old age of layers when they were subjected to molting. Bar et al. (2001) subjected layers of different age groups to molting and reported better production when birds were molted younger.

In the present study, the highest egg production was achieved in more than $85 \%$ in the layers molted the age of 85 weeks. Thirunavukkarasu et al. (2009) reported that molting at 75 weeks of age gave resulted egg production. Further, it was noted that, compared with60-week-old non-molted layers, molted layers performed better in terms of egg production and livability. The findings are also consistent with those of Bar et al. (2001) that molting improved egg production. The length of the second egg laying cycle in the present study was 48 weeks in an open house and birds were culled due to low production. In other studies, the second laying cycle reported is variable and this might be due to the control environment practiced in most of the developed countries.

In the present study feed cost played a significant role in the net gain during egg laying cycle. It is worth noting that the net gain was comparatively lower in the weeks when there was maximum production (Figure 1). This is a result of decreased demand and low egg price during the summer months. There is no egg marketing control system in the area and the demand fluctuates according to season and random events. Layers were kept for 48 weeks in the second laying cycle, although egg production was less than $70 \%$ in week 45 , but the price of the egg in the market helped to keep the operation running.

\section{CONCLUSION}

In conclusion, it is suggested that the layers that completed their first egg laying cycle can be successfully rejuvenated for the second laying cycle. However, the season and procedure adopted for molting have significant influence on the mortality, cost, egg production and profits obtained in the next laying cycle.

\section{REFERENCES}

Alodan MA, Mashaly, MM. Effect of induced molting in laying hens on production and immune parameters. Poultry Science 1999;78:171177.

Andrews DK, Berry WD, Brake J. Effect of lighting programme and nutrition on reproductive performance of molted single comb white leghorn hens. Poultry Science 1987;66:1298-1305

Baker M, Brake J, McDaniel GR. The relationship between body weight loss during an induced molt and post molt egg production, egg weight, and shell quality in caged layers. Poultry Science 1983;62:409-413.

Baranczuk E, Czarnowski D, Namiot Z. Effect of fasting on some enzymatic activities in the muscle layer of intestine in the rat. RoczAkad Med Bialymst 1995;40:260-266

Bar A, Razaphkovsy V, Wax E, Malka Y. Effect of age at molting on post molting performance. Poultry Science 2001;80:874-878.

Bar A, Vax E, Striem S. Relationships among age, eggshell thickness and vitamin D metabolism and its expression in the laying hen. Comparative Biochemistry and Physiology 1999;123:147-154.

Bass PD, Hooge DM, Koutsos EA. Dietary thyroxine induces molt in chickens (Gallus gallusdomesticus). Comparative Biochemistry and physiology 2007; 146:335-341

Bell DD. Historical and current molting practices in the U.S. Table egg industry Poultry Science 2003;82:965-970.

Bell DD, Adams CJ. First and second cycle egg production characteristics in commercial table egg flock. Poultry Science 1992;1:44-459.

Bell DD, Kuney DR. Effect of fasting and post-fast diets on performance in molted flocks. Applied Poultry Research 1992;1:208-206.

Bell DD. Effect of fasting and post-fast diets on performance in molted flocks. Journal Applied Poultry Research 1992;1:200-206.

Berry WD. The physiology of forced molting. Poultry science 2003;82:971980.

Berry WD, Brake J. Post-molt performance of laying hens molted by high dietary zinc, low dietary sodium, and fasting; Egg production and shell quality. Poultry Science 1987;66:218-226.

Brake J, Thaxton P. Physiological changes in caged layers during a molt. 2. Gross changes in organs. Poultry Science 1979;58:707-716.

Carter TA, Ward JB. Limited and full feeding of layers during the non-laying period of a molting cycle [abstr.). Poultry Science 1981;60:1635.

Halaby WS. Effect of feeding different levels of treated ervil seeds on the performance of broilers and layers [thesis]. Beirut: American University of Beirut, Beirut. Lebanon; 1997. 
Harms RH. The influence of removing sodium or chloride from the diet of commercial laying hens [abstract]. Poultry Science 1990; 69: 171

Hasan ZU, Sultan JI, Akram M. Nutritional manipulations during induced molt in white leghorn layers 2. Effect on percent hen day egg production, body weight and reproductive system. International Journal Agriculture \& Biology 2000; 2:318-321.

Hassanabadi A, Kermanshahi $H$. Effect of force molting on post molt performance of laying hens. Int. Journal Of. Poultry Science 2007;6(9):630-633.

Hurwitz S, Wax E, Nisenbaum Y, Ben Moshe M, Plavnikl. The response of laying hens to induced molt as affected by strain and age. Poultry Science 1998; 77:22-31.

Hussein AS. Induced molting procedures in laying fowl. World's Poultry Science Journal 1996;52:175-187.

Kashmiri LA, Vatsalya V. Deleterious Effects of Molting on the Morphophysiology of Japanese Quail Layers (Coturnix japonica). International Journal Poultry Science 2011;10:120-124.

Koelkebeck KW, Parsons CM, Leeper RW, Moshtaghian J. Effect of protein and methionine levels in molt diets on post-molt performance of laying hens. Poultry Science 1991;70:2063-2073.

Ocak N, Sarica M, ErenerG, Garipoglu AV. The effect of body weight prior to molting in brown laying hens on egg yield and quality during second production cycle. Int. Journal of Poultry. Science 2004;3:768-772.

Oguike MA, Igboeli G, Ibe SN, Uzoukwu1M, Akomas SC, Ironkwe MO. Morphological characteristics and egg production of forced-molt layers under different molt induction techniques. African Journal Biotechnology 2005; 4(9):1001-1004.

Peebles ED, Burnham MR, Walzem RL, Branton SL, Gerard PD. Effects of fasting on serum lipids and lipoprotein profiles in the egg-laying hen (Gallus domesticus). Comparative Biochemistry and Physiology, Part A 2004;138:305-311.

Swanson $\mathrm{MH}$, Bell DD. Field tests of forced molting practices and performance in commercial egg production flock. Proceedings of the 14th World's Poultry Congress; 1971; Madrid. Espanha: Ministério da Agricultura; 1971. p.87-97.

Thirunavukkarasu P, Moorthy M, Viswanathan K, Edwin SC. Egg production performance of induced molted white leghorn layers. Tamilnadu Journal Veterinary \& Animal Sciences 2009;5:117-119.

Wu G, Gunawardana P, Bryant MM, Voitle RA, Roland DASr. Effect of Molting Method and Dietary Energy on Postmolt Performance, Egg Components, Egg Solid, and Egg Quality in Bovans White and Dekalb White Hens During Second Cycle Phases Two and Three. Poultry Science 2007;86:869-876. 